\title{
The Frequency of $\mathrm{A1298C}$ and C677T Polymorphisms of the Methylentetrahydrofolate Gene in Turkish Patients with Rheumatoid Arthritis: Relationship with Methotrexate Toxicity
}

\author{
Özgür Taşbaş ${ }^{1}$, Pınar Borman ${ }^{*}, 1$, Halil Gürhan Karabulut ${ }^{2}$, Ajlan Tükün ${ }^{2}$ and Rezan Yorgancığlu ${ }^{1}$ \\ ${ }^{I}$ Ankara Training and Research Hospital I. Clinic of Physical Medicine and Rheumatology, Cebeci, Ankara, Turkey \\ ${ }^{2}$ University of Ankara, Faculty of Medicine, Dept of Genetics, Sihhiye, Ankara, Turkey
}

\begin{abstract}
The C677T and A1298C polymorphisms of methylenetatrahydrofolate reductase (MTHFR) gene are reported to have a relationship to methotrexate (MTX) metabolism, with conflicting results. The aim of this study was to determine the frequency of MTHFR C677 T and A1298C gene polymorphisms in a group of Turkish RA patients and evaluate its association with MTX toxicity.

Sixty-four patients with RA and 31 control subjects with a mean age of $48.7 \pm 12.5$ and $46.2 \pm 13.4$ years, were enrolled to the study. Demographic characteristics were obtained and MTX-related adverse effects were recorded in the patient group. The A1298C and C677T polymorphisms of the MTHFR gene were analyzed and the distribution of genotypes according side effects, were determined.

The frequency of MTHFR C677T and A1298C polymorphisms were similar in the patient and control groups. Folic acid supplementation with a mean dose of $5 \mathrm{mg}$ folic acid/week, was present in all patients. Thirty-six of the 64 patients showed adverse effects to MTX treatment, and MTX had been discontinued in $12(18.8 \%)$ patients due to side effects and/or inefficacy. MTHFR C677T and A1298C gene polymorphisms were found to be similar in patients with and without MTX-related adverse events.

In conclusion, A1298C and C677T polymorphisms in the MTHFR gene, were not related with MTX-related toxicity in RA patients receiving folate supplementation. Further studies are needed to illuminate the polymorphisms in other enzymes that might be responsible from the MTX toxicity in patients suffering from RA.
\end{abstract}

Keywords: Rheumatoid arthritis, methotrexate, MTHFR gene, A1298C polymorphism, C677T polymorphism, folate.

\section{INTRODUCTION}

Rheumatoid arthritis is a chronic systemic rheumatic condition, characterized by joint inflammation, cartilage degradation and bone erosion. Methotrexate (MTX) is the cornerstone and the most common used disease-modifying antirheumatic drug (DMARD) for the treatment of RA and has been shown to reduce disease activity and stabilize the development of bone erosions [1]. Many aspects about the pharmacology of MTX are not clear. Despite the well accepted efficacy of MTX, response to the drug and adverse effects in RA patients are not universal. Although some patients experience good clinical response, some have to discontinue therapy due to adverse effects. At the present time there are no reliable tests or assessments that can predict the toxicity of MTX. A better understanding of its pharmacology can be gained by using the principles of pharmacogenetics to study genetic differences (polymorphisms) in the enzymes involved in the metabolic pathways of MTX [2-5]. There has recently been an interest in the association of folate pathway polymorphisms with the adverse events of MTX. In recent years several studies have

*Address correspondence to this author at the Birlik Mahallesi Zirvekent Mimoza Sitesi, A-1 Blok No: 59, Çankaya, Ankara, Turkey;

Tel: 90.5324649897; E-mail: pinarborman@gmail.com demonstrated polymorphism of the genes regulating enzymes in the intracellular MTX metabolic pathway, with conflicting results [6-21]. Two single nucleotide polymorphisms of methylene tetrahydrofolate (MTHFR) C677T and A1298C have been widely studied in the efficacy and/or toxicity of MTX [8-24].

The aim of this study was to determine the frequency of MTHFR C677 T and A1298C gene polymorphism in a group of Turkish RA patients and evaluate its association with MTX toxicity.

\section{MATERIALS AND METHODS}

A hundred and four patients with RA, who met the ACR revised criteria [25] for RA, were enrolled from the outpatient clinics of Ankara Training and Research Hospital, Rheumatology unit of Physical Medicine and Rehabilitation Clinic, between 2009 January and August 2009. Current or past treatment with MTX was the main criterion for the inclusion of RA patients into the study. Patients with a mean BMI $>35$, aged $<18$, and $>80$ years, having B12 and folic acid depletion and patients with these comorbid diseases (chronic renal failure, hepatic insufficiency, thyroid disease, heart failure and uncontrolled diabetes mellitus) were not included to the study. 104 patients with rheumatoid arthritis were assessed for eligibility. 98 patients had current or past MTX treatment, 5 patients refused to participate in the study and 
29 patients were excluded due to age or comorbid diseases. Therefore 64 RA patients were included to the study. Thirtyone age and sex similar (within +2 years) healthy control subjects who were the members of the hospital staff and volunteered to participate in the study, were comprised. We obtained informed consent from all the patients and controls, and the study was approved by the ethics committee of the hospital.

Demographic characteristics including age, sex, body mass index of all subjects, and drug intake and disease duration of RA patients were recorded. All patients underwent a clinical interview and physical examination to determine MTX related adverse events.

Methotrexate-related adverse effects were defined as one or a combination of gastrointestinal symptoms (nausea, abdominal pain, diarrhoea) appearing repeatedly in association with methotrexate consumption, oral ulcers, disturbed liver function tests (alanine aminotransferase and aspartame aminotransferase more than twice the upper limit of normal values), methotrexate induced or aggravated skin nodules, and haematological adverse reactions (leucocyte count below $355 / \mathrm{mm}^{3}$ ). Side effects were recorded during patient recruitment and from the files $[12,26]$.

Blood samples of the patients were taken to determine hemoglobin $(\mathrm{Hb})$, erythrocyte sedimentation rate (ESR) using the Westergren method, rheumatoid factor (RF) using nephelometric method and $\mathrm{C}$ reactive protein (CRP) by turbidimetric method in RA group. The numbers of tender and swollen joints as well as disease and treatment duration were collected from patient files. DAS 28 was calculated for each patient using well-known calculations which included the number of tender and swollen joints, ESR and patients' global assessment of general health expressed on visual analog scale [27]. The scores of Health Assessment Questionnaire (HAQ) indicating the functional status of RA patients were recorded from the files [28]. The ESR, CRP, DAS28 and HAQ, were considered as disease activity parameters.

Genomic DNA was prepared from peripheral blood of patients and controls. The A1298C and C677T polymorphisms of the MTHFR gene were analyzed by polymerase chain reaction amplification, restriction enzyme digestion, and DNA fragment separation by electrophoresis, as described previously. Allelic frequencies and genotype distributions among groups were compared. The distribution of genotypes according to disease variables and side effects were also analyzed [29].

\section{Statistical Analysis}

Descriptive statistics were performed and indicated as mean \pm standard deviation and median (maximum-minimum) for continuous variables. All qualitative data are expressed as frequencies and percentages. The normality of the distribution of continuous variables was analyzed by Shapiro Wilk test. Differences in genotype distribution were tested with two sided chi-square test. The intergroup comparisons for continuous variables between the two groups (with and without polymorphism) were performed by student $t$ test and Mann Whitney U test. Spearman's correlation test was used to evaluate correlation between continuous variables and Pearson's chi square test or Fisher's exact outcome chi square tests were used to define the categorical variables. Kruskal Wallis test was performed for comparison of more than two groups. The level of significance was set to 0.05 . All statistical analyses were done using SPSS for windows version 11.5 programme.

\section{RESULTS}

A total of 64 RA patients and 31 control subjects were enrolled to the study. Characteristics of RA patients and control subjects are presented in Table 1. There was no statistical difference between the mean age, sex and BMI of the patient and control subjects ( $p>0.05)$. Most patients were receiving MTX at the time of enrollment but some had discontinued MTX treatment due to adverse effects. Folic acid supplementation with a mean dose of $5 \mathrm{mg}$ folic $\mathrm{acid} /$ week, was present in all patients.

Table 1. Demographic and Clinical Characteristics of Patients and Controls

\begin{tabular}{|c|c|c|}
\hline & $\begin{array}{c}\text { Patients } \\
(\mathbf{n}=\mathbf{6 4})\end{array}$ & $\begin{array}{c}\text { Controls } \\
(\mathbf{n}=\mathbf{3 1})\end{array}$ \\
\hline \hline age (mean \pm SD) & $48.7 \pm 12.5$ & $46.2 \pm 13.4$ \\
\hline Sex (female/male) & $53 / 11$ & $26 / 5$ \\
\hline BMI $\left(\mathrm{kg} / \mathrm{m}^{2}\right)$ & $27.0 \pm 5.0$ & $27.5 \pm 4.7$ \\
\hline Duration of the disease (years) & $6.5(0.50-34)$ & \\
\hline Duration of MTX treatment (years) & $2(0.2-10)$ & \\
\hline Concurrent DMARD treatment (n) (\%) & $34(53.1 \%)$ & \\
\hline Rheumatoid factor positivity (n)(\%) & $41(64.1 \%)$ & \\
\hline $\begin{array}{l}\text { BMI: Body mass index, MTX: Methotrexate, DMARD: Disease-modifying } \\
\text { antirheumatic drugs. }\end{array}$ &
\end{tabular}

The mean duration and dose of the MTX were 2 years (0.2-10) and $15 \mathrm{mg} /$ week (10-20) respectively. 34 (53.1\%) patients were using MTX and other DMARDs. Of those 18 $(52.9 \%)$ patients were on sulphasalasine, $8(23.5 \%)$ patients were on hydroxychloroquine, $2(5.8 \%)$ patients were on leflunamide and $6(17.6 \%)$ patients were on both HCQ and SLZ, in addition to MTX. 18 (28.1\%) and $39(60.9 \%)$ patients were using corticosteroids and NSAII drugs respectively. $38(59.4 \%)$ patients were using oral MTX, while $26(40.6 \%)$ patients were on subcutaneous MTX therapy.

Thirty-six of the 64 patients $(56.2 \%)$ had experienced adverse effects to MTX treatment, of which gastrointestinal toxicity was the most common. MTX had been discontinued in $12(18.8 \%)$ patients due to adverse side effects and/or inefficacy. Table 2 indicates the frequency of MTX-related adverse effects among the patients. There was no significant difference in the MTX dosage, the demographic and clinical features between the patients with and without adverse effects during MTX treatment ( $\mathrm{p}>0.05)$.

The frequencies of MTHFR A1298C and C677T polymorphisms were determined in all subjects and were found to be statistically similar between patient and control groups (Table 3). The distribution of allele polymorphisms in regard to MTX-related adverse events were carried out. MTHFR C677T and A1298C gene polymorphisms were 
found to be similar in patients with and without MTX-related adverse events (Table 4). In order to define the relationship between MTX-related side effects and polymorphisms in MTHFR genes, we have analyzed the patients receiving only MTX treatment. The distribution of MTHFR A1298C and C677T polymorphisms in patients with and without adverse effects, were again found to be similar (Table 5).

Table 2. The Frequency of Methotrexate-Related Adverse Effects in Patients with Rheumatoid Arthritis

\begin{tabular}{|l|c|}
\hline & $\mathbf{n}(\mathbf{\%})$ \\
\hline \hline General & \\
Fatigue & $18(28.1 \%)$ \\
Malaise & $14(21.9 \%)$ \\
\hline Gastrointestinal & \\
Nausea or vomiting & $20(31.3 \%)$ \\
Disturbed liver function tests & $6(9.4 \%)$ \\
\hline Haematological & $\mathbf{2 ( 3 . 1 \% )}$ \\
\hline Pulmonary & $\mathbf{5 ( 7 . 8 \% )}$ \\
\hline Mucocutaneous & $\mathbf{1 5}(\mathbf{2 3 . 4 \% )}$ \\
\hline Ear, nose, throat & $\mathbf{3 ( 4 . 7 \% )}$ \\
\hline Neuropsychiatric & $\mathbf{2 ( 3 . 1 \% )}$ \\
\hline
\end{tabular}

polymorphisms were observed in the patient group.

\section{DISCUSSION}

This study showed that the frequency of MTHFR A1298C and C677T polymorphisms were similar in Turkish RA patients and healthy control subjects. The prevalence of the MTHFR C677T and A1298C genotypes in our cohort of patients were $45 \%$ for $677 \mathrm{CC}, 43 \%$ for $\mathrm{C} 677 \mathrm{~T}$ and $10 \%$ for $677 \mathrm{TT}$, and $37 \%$ for $1298 \mathrm{AA}, 48 \%$ for $1298 \mathrm{AC}$, and $14 \%$ for $1298 \mathrm{CC}$; which were comparable with some previous results $[12,14,19]$.

The frequency of the C677T polymorphism homozygosity was lower in our study as compared to previous studies which could be related to ethnic differences [18]. Ghodke et al. and Berkun et al. determined a significantly higher incidence of A1298C polymorphism in their RA group than in general population $[9,16]$.

The present study shows that genetic polymorphisms in the MTHFR gene do not influence the toxicity of MTX treatment in RA patients receiving folate supplementation. The influence of MTHFR C677T and 1298C polymorphisms on the toxicity of MTX treatment has been widely studied, however conflicting results have been reported [8-19]. In some previous studies the presence of MTHFR A1298C polymorphism was associated with a higher incidence of MTX-related toxicity. Wessels et al. observed more adverse events in MTHFR $1298 \mathrm{C}$ allele carriers in their early RA

Table 3. The Distribution of Genotypes (A1298C and C677T Polymorphisms) in RA and Control Groups

\begin{tabular}{|c|c|c|c|c|}
\hline & RA (n=64) & Control (n=31) & p & Odds Ratio (\% CI) \\
\hline \hline $\mathbf{6 7 7} \mathbf{C C}$ & $29(45.3 \%)$ & $20(64.5 \%)$ & - & $1.000^{\mathrm{a}}$ \\
\hline $\mathbf{6 7 7} \mathbf{C T}$ & $28(43.8 \%)$ & $10(32.3 \%)$ & $\mathrm{ns}$ & $1.931(0.770-4.844)$ \\
\hline $\mathbf{6 7 7} \mathbf{~ T T}$ & $7(10.9 \%)$ & $1(3.2 \%)$ & $\mathrm{ns}$ & $4.828(0.550-42.339)$ \\
\hline $\mathbf{1 2 9 8} \mathbf{~ A A}$ & $24(37.5 \%)$ & $6(19.4 \%)$ & $\mathrm{ns}$ & $1,000^{\mathrm{a}}$ \\
\hline $\mathbf{1 2 9 8} \mathbf{~ A C}$ & $31(48.4 \%)$ & $16(51.6 \%)$ & 0.035 & $0.484(0.165-1.425)$ \\
\hline $\mathbf{1 2 9 8} \mathbf{C C}$ & $9(14.1 \%)$ & $9(29.0 \%)$ & & $0.250(0.069-0.905)$ \\
\hline
\end{tabular}

CI: condidence interval a reference category.

${ }^{a}$ Reference Genotype.

The distribution of disease activity parameters in regard to allele polymorphisms, were also determined. No statistical difference between ESR, CRP, HAQ and DAS 28 values in regard to MTHFR A1298C (Table 6) and C677T (Table 7) patients as also confirmed by study group of Derwieux et al. and Mena et al. [11, 14, 24]. On the other hand, Grabar et al. reported a protective effect of MTHFR A1298C polymorphism on overall MTX toxicity, and MTHFR

Table 4. The Genotypic Distribution of RA Patients According to Presence of Adverse Events

\begin{tabular}{|c|c|c|c|c|}
\hline & Adverse Events (-) $(\mathbf{n}=\mathbf{2 8})$ & Adverse Events (+) (n=36) & P & Odds Ratio (\%95 CI) \\
\hline \hline $\mathbf{6 7 7} \mathbf{C C}$ & $12(42.9 \%)$ & $17(47.2 \%)$ & $\mathrm{ns}$ & $0.814(0.286-2.322)$ \\
\hline $\mathbf{6 7 7} \mathbf{C T}$ & $13(46.4 \%)$ & $15(41.7 \%)$ & $\mathrm{ns}$ & $0.941(0.177-4.997)$ \\
\hline $\mathbf{6 7 7} \mathbf{~ T T}$ & $3(10.7 \%)$ & $4(11.1 \%)$ & - & $1,000^{\mathrm{a}}$ \\
\hline $\mathbf{1 2 9 8} \mathbf{A A}$ & $12(42.9 \%)$ & $12(33.3 \%)$ & $\mathrm{ns}$ & $1.818(0.613-5.391)$ \\
\hline $\mathbf{1 2 9 8} \mathbf{A C}$ & $11(39.3 \%)$ & $20(55.6 \%)$ & $\mathrm{ns}$ & $0.800(0.172-3.728)$ \\
\hline $\mathbf{1 2 9 8} \mathbf{C C}$ & $5(17.9 \%)$ & $4(11.1 \%)$ & & \multicolumn{2}{c|}{} \\
\hline
\end{tabular}

CI: Confidence interval a Reference category.

${ }^{a}$ Reference Genotype. 
1298CC genotype was found to be inversely associated with MTX-related adverse events in some previous studies [15, 16]. MTHFR C677T polymorphism was also reported to be associated with MTX-related adverse events in some previous studies $[8,10,19,21]$. Spelatos et al. illustrated an inverse relationship between MTHFR C677T polymorphism and MTX related toxicity in a group of patients with autoimmune diseases in which the presence of toxicity was more common in patients with the normal $677 \mathrm{CC}$ genotype [12]. In contrast to these studies, no association between the C677T and/or A1298C polymorphisms and MTX-related side effects was reported by some previous authors, supporting our results $[9,12,13,16,17]$. Our results are in agreement also with the findings of Ghodke et al. and Taraborelli et al. that neither MTHFR A1298C nor C677T polymorphisms have associated with MTX-related adverse effects in Turkish RA patients, similar to Indian and Italian RA groups $[9,17]$. In a recent meta-analysis with a total of 1514 patients with RA, no association was determined between the C677T and A1298C polymorphisms of MTHFR gene and the toxicity of MTX in RA patients [20].

The discordance and inconsistency of some previous studies and our data can be explained by the characteristics of the study group, therapeutic doses and particularly the prescription of folate supplementation. In the earlier studies the doses used for MTX treatment were lower and majority of the patients were not receiving folate supplementation and the proportion of patients who had discontinued MTX due to adverse effects were much higher than in our study $[8,10$, 19]. Similar to our data, majority of the patients in some previous studies, were receiving concomitant folic acid and discontinuation rates of MTX due to adverse events, were comparable to the results of our study [12-14, 17]. This can be due to the counteracting effects of folate supplementation on deleterious effects of these MTHFR gene polymorphisms in patients with RA on MTX treatment. The molecular basis for this effect could be the protection of MTHFR enzyme from thermal inactivation by folate supplementation $[13,14]$. Our study strengthens the role of folic acid supplementation

Table 5. The Genotypic Distribution According to Adverse Events in Patients Receiving Only Methotrexate Treatment

\begin{tabular}{|c|c|c|c|}
\hline & $\begin{array}{c}\text { Adverse Events (-) } \\
(\mathbf{n}=13)\end{array}$ & $\begin{array}{c}\text { Adverse Events (+) } \\
(\mathbf{n}=\mathbf{1 7})\end{array}$ & $\mathbf{p}$ \\
\hline \hline $\mathbf{1}$ & & & $\mathrm{ns}^{\mathrm{a}}$ \\
\hline $\mathbf{6 7 7} \mathbf{C C}$ & $7(53.8 \%)$ & $9(52.9 \%)$ & \\
\hline $\mathbf{6 7 7} \mathbf{C T}$ & $4(30.8 \%)$ & $5(29.4 \%)$ & \\
\hline $\mathbf{6 7 7} \mathbf{~ T T}$ & $2(15.4 \%)$ & $3(17.6 \%)$ & \\
\hline $\mathbf{2}$ & & & $\mathrm{ns}^{\mathrm{a}}$ \\
\hline $\mathbf{1 2 9 8} \mathbf{A A}$ & $8(61.5 \%)$ & $5(29.4 \%)$ & \\
\hline $\mathbf{1 2 9 8} \mathbf{A C}$ & $4(30.8 \%)$ & $9(52.9 \%)$ & \\
\hline $\mathbf{1 2 9 8} \mathbf{C C}$ & $1(7.7 \%)$ & $3(17.6 \%)$ & \\
\hline
\end{tabular}

${ }^{a}$ Comparisons in terms of the distibutions of genotypes.

Likelihood ratio test.

on preventing the toxicity of MTX even in patients that had

Table 6. The Distributions of Disease Activity Parameters According to MTHFR C677T Polymorphism in RA Patients

\begin{tabular}{|c|c|c|c|}
\hline & $\mathbf{C C}(\mathbf{n = 2 9 )}$ & $\mathbf{C T}(\mathbf{n = 2 8})$ & $\mathbf{p}^{\mathbf{a}}$ \\
\hline \hline HAQ (median) & $0.75(0-3)$ & $0.9(0-3)$ & $0.25(0-1.75)$ \\
\hline DAS28 (median) & $4.1(1,9-7,8)$ & $4.2(1.7-7.5)$ & $4.2(2.7-5.4)$ \\
\hline Larsen Score (median) & $2.0(1.0-5.0)$ & $2.5(1.0-5.0)$ & 0.239 \\
\hline ESR (median) & $39.0(3.0-82.0)$ & $25.0(2.0-120.0)$ & 0.735 \\
\hline CRP (median) & $0.9(0.2-10.5)$ & $0.6(0.1-10.0)$ & 0.054 \\
\hline
\end{tabular}

${ }^{\mathrm{a} A n a l y s i s ~ o f ~ v a r i a n c e ~ a m o n g ~ t h e ~ g e n o t y p e s ~} \mathrm{~b}$ Comparisons between CC and CT+TT.

HAQ: The Health Assessment Questionnaire, DAS 28: Disease Activity Score, ESR: erythrocyte sedimentation rate, CRP: C- reactive protein, MTX: Methotrexate, DMARD Disease-modifying antirheumatic drugs.

NSAII: Nonsteroidal anti-inflammatory drugs.

Table 7. The Distribution of Disease Activity Parameters According to MTHFR A1298C Polimorphism in RA Patients

\begin{tabular}{|c|c|c|c|c|}
\hline & AA (n=24) & AC (n=31) & $\mathbf{p}^{\mathbf{a}}$ \\
\hline \hline HAQ (median) & $0.5(0-2.5)^{\mathrm{b}}$ & $1.1(0-3)^{\mathrm{b}, \mathrm{c}}$ & $0.25(0-1.6)^{\mathrm{c}}$ & 0.005 \\
\hline DAS28 (median) & $4.1(2.4-6.9)$ & $4.3(1.7-7.8)$ & $3.4(2.6-5.8)$ \\
\hline Larsen Score (median) & $2.0(1.0-5.0)$ & $3.0(1.0-5.0)$ & $2.0(1.0-5.0)$ & 0.347 \\
\hline ESR (median) & $26.5(6.0-120.0)$ & $36.0(2.0-110.0)$ & $29.0(3.0-50.0)$ & 0.344 \\
\hline CRP (median) & $0.7(0.2-10.0)$ & $0.8(0.1-10.5)$ & $0.5(0.2-2.5)$ & 0.386 \\
\hline
\end{tabular}

${ }^{a}$ Analysis of variance among the genotypes

${ }^{\mathrm{b}}$ Statistically significant difference between AA and $\mathrm{AC}(\mathrm{p}=0,003)$.

${ }^{\mathrm{c}}$ Statistically significant difference between $\mathrm{AC}$ and $\mathrm{CC}(\mathrm{p}=0,002)$.

HAQ: The Health Assessment Questionnaire, DAS 28: Disease Activity Score, ESR: Sedimentation, CRP: C- reactive protein, MTX: Methotrexate, DMARD: Disease-modifying antirheumatic drugs, NSAII: Nonsteroidal anti-inflammatory drugs. 
polymorphisms in MTHFR gene. Polymorphisms in enzymes other than MTHFR may have some correlation with the clinical toxicity of MTX in RA patients particularly on folate supplementation and needs to be further studied.

MTX inhibits the enzyme dihydrofolate reductase, thereby depleting the pool of reduced folates and producing a state of effective folate deficiency. Folic acid supplementation was shown not to antagonize the therapeutic response but there is no definite consensus regarding the use of folate supplements in patients taking MTX. Regional and national differences in practice remain pronounced. Folic acid improves MTX tolerability rates without compromising efficacy. $5 \mathrm{mg}$ /day folic acid has been proposed to be given in all patients receiving MTX therapy $[30,31]$. In our study all of the patients were on concomitant folic acid supplementation, which might be a limitation of our study. It would be valuable to study these gene expressions according to side effects of MTX, in both patients on folate supplementation and in patients not receiving this supplementation.

Our results also indicate that the disease activity parameters, which may be a reflection of MTX efficacy, were similar between the groups with and without polymorphisms in MTHFR A1298C and C677T genes. Similar to our study, most of the previous studies have not found any association between C677T and A1298 C polymorphisms and efficacy of MTX treatment in RA patients [9, 17, 20, 23]. On the other hand, Kurzawski et al. [22] indicated an association with MTHFR 677T and 1298C alleles, and increased rate of remission in RA patients treated with MTX, supporting some of the previous reports [8, 14].

In conclusion, A1298C and C677T polymorphisms in the MTHFR gene, were not related with MTX toxicity in Turkish RA patients receiving folate supplementation. Further studies are needed to illuminate the polymorphisms in other enzymes that might be responsible from clinical toxicity of MTX in patients suffering from RA.

\section{DISCLOSURE}

None declared.

\section{REFERENCES}

[1] Johnsen AK, Weinblatt ME. Methotrexate In: Hochberg MC, Silman AJ, Smolen JS, et al., Eds. Rheumatology $5^{\text {th }} \mathrm{ed}$. Philadelphia, Mosby-Elsevier 2011; pp. 509-18.

[2] Weisman MH, Furst DE, Park GS, et al. Risk genotypes in folate dependent enzymes and their association with methotrexate related side effects in rheumatoid arthritis. Arthritis Rheum 2006; 54: 60712 .

[3] Stamp L, Roberts R, Kennedy M, Barclay M, O'Donnell J, Chapman P. The use of low dose methotrexate in rheumatoid arthritis - are we entering a new era of therapeutic drug monitoring and pharmacogenomics? Biomed Pharmacother 2006; 60: 678-87.

[4] Taniguchi A, Kamatani N. Pharmacogenetic approaches to rheumatoid arthritis. Pharmacogenomics J 2004; 4: 350-3.

[5] Evans WE. Differing effects of methylene tetrahydrofolate reductase single nucleotide polymorphisms on methotrexate efficacy and toxicity in rheumatoid arthritis. Pharmacogenetics 2002; 12: 181-2.

[6] Ranganathan P, Culverhouse, Marsh S. Methotrexate gene polymorphisms and their effects on MTX toxicity in Caucasian and African American patients with rheumatoid arthritis. J Rheumatol 2008; 5: 559-69.

[7] Fujimaki C, Hayashi H, Tsuboi S, et al. Plasma total homocysteine level and methylene tetrahydrofolate reductase $677 \mathrm{C}>\mathrm{T}$ genetic polymorphism in Japanese patients with rheumatoid arthritis. Biomarkers 2009; 14: 49-54.

[8] Urano W, Taniguchi A, Yamanaka H, et al. Polymorphisms in the methylenetetrahydrofolate reductase gene were associated with both the efficacy and the toxicity of methotrexate used for the treatment of rheumatoid arthritis, as evidenced by single locus and haplotype analyses. Pharmacogenetics 2002; 12: 183-90.

[9] Ghodke Y, Chopra A, Joshi K, Patwardhan B. Are thymidilate synthase and methylene tetrahydrofolate reductase genes linked with methotrextae response (efficacy, toxicity) in Indian (Asian) rheumatoid arthritis patients. Clin Rheumatol 2008; 27: 787-9.

[10] Kumagai K, Hiyama K, Oyama T, Maeda H, Kohno N. Polymorphisms in the thymidylate synthase and methylenetetrahydrofolate reductase genes and sensitivity to the low-dose methotrexate therapy in patients with rheumatoid arthritis. Int J Mol Med 2003; 11: 593-600.

[11] Dervieux T, Greenstein N, Kremer J. Pharmacogenomic and metabolic biomarkers in the folate pathway and their association with methotrexate effects during dosage escalation in rheumatoid arthritis. Arthritis Rheum 2006; 54: 3095-103.

[12] Spelatos M, Papadopoulos N, Daiou C, Katodritou E, PavlitouTsiontsi A, Galaropoulou V. Relationship between 5,10 metylene tetrahydrofolate reductase C677T gene polymorphism and methotrexate related toxicity in patients with autoimmune diseases receiving folic acid supplementation. Ann Rheum Dis 2005; 64 : 1791-2.

[13] Aggarwal P, Naik S, Mishra KP, Aggarwal A, Misra R. Correlation between methotrexate efficacy and toxicity with C677T polymorphism of the methylene tatrahydrofolate gene in rheumatoid arthritis patients on folate supplementation. Indian Med J 2006; 124: 521-6.

[14] Wessels J, Bouwstra J, Heijmans BT, et al. Efficacy and toxicity of methotrexate in early rheumatoid arhritis are associated with single-nucleotide polymorphisms in genes coding for folate pathway enzymes. Arthritis Rheum 2006; 54: 1087-95.

[15] Grabar BP, Logar D, Lestan B, Dolzan V. Genetic determinants of methotrexate toxicity in rheumatoid arthritis patients: a study of polymorphisms affecting methotrexate transport and folate metabolism. Eur J Clin Pharmacol 2008; 64: 1057-68.

[16] Berkun Y, Levatovsky D, Rubinow A et al. Methotrexate related adverse effects in patients with rheumatoid arthritis are associated with the A1298C polymorphism of the MTHFR gene. Ann Rheum Dis 2004; 63: 1227-31.

[17] Taraborelli M, Andreoli L, Archetti S, Ferrari M, Cattaneo R, Tincani A. Metylene tetrahydrofolate reductase polymorphisms and methotrexate: no associaiton with response to therapy nor with drug-related adverse events in an Italian population of rheumatic patients. Clin Exp Rheumatol 2009; 27(3): 499-502.

[18] Hughes LB, Beasley TM, Patel H, et al. Racial or ethnic differences in allele frequencies of single nucleotide polymorphisms in the methylene tetrahydrofolate reductase gene and their influence on response to methotrexate in rheumatoid arthritis. Ann Rheum Dis 2006; 65: 1213-8.

[19] Van Ede AE, Laan RF, Blom HJ, et al. The C677T mutation in the methylenetetrahydrofolate reductase gene: a genetic risk factor for methotrexate- related elevation of liver enzymes in rheumatoid arthritis patients. Arthritis Rheum 2001; 44: 2525-30.

[20] Lee YH, Song GG. Associations between the C677T and A1298C polymorphisms of MTHFR and the efficacy and toxicity of methotrexate in rheumatoid arthritis: a meta-analysis. Clin Drug Investig 2010; 30(2): 101-8.

[21] Haagsma CJ, Blom HJ, van Riel PL, et al. Influence of sulphasalazine, methotrexate, and the combination of both on plasma homocysteine concentrations in patients with rheumatoid arthritis. Ann Rheum Dis 1999; 58: 79-84.

[22] Kurzawski M, Pawlik A, Safranow K, Herzynska M, Drozdzik M. $677 \mathrm{C}>\mathrm{T}$ and $1298 \mathrm{~A}>\mathrm{C}$ MTHFR polymorphisms affect methotrexate treatment outcome in rheumatoid arthritis. Pharmacogenomics 2007; 8(11): 1551-9.

[23] Stamp LK, Chapman PT, O’Donnell JL, et al. Polymorphisms within the folate Pathway predict folate concentrations but are not associated with disease activity in rheumatoid arthritis patients on methotrexate. Pharmacogenet Genomics 2010; 20(6): 367-76.

[24] Mena JP, Salazar-Paramo M, Gonzalez-Lopez L, et al. Polymorphisms C677T and A1298C in the MTHFR gene in Mexican patients with 
rheumatoid arthritis treated with methotrexate: implication with elevation of transaminases. Pharmacogenomics J 2011; 11: 287-91.

[25] Arnett FC, Edworthy SM, Bloch DA, et al. The American Rheumatism association 1987 revised criteria for the classification of rheumatoid arthritis. Arthritis Rheum 1988; 31: 315-24.

[26] Fries JF, Spitz PW, Williams CA, Bloch DA, Singh G, Hubert HB. A toxicity index for comparison of side effects among different drugs. Arthritis Rheum 1990; 33: 121-30.

[27] Van der Heijde DM, van 't Hof MA, van Riel PL, et al. Judging disease activity in clinical practice in rheumatoid arthritis: first step in the development of a disease activity score. Ann Rheum Dis 1990; 49: 916-20.
[28] Bruce B, Fries JF. The Health Assessment Questionnaire (HAQ). Clin Exp Rheumatol 2005; 23(5 Suppl 39): 14-8.

[29] Miller SA, Dykes DD, Polesky HF. A simple salting out procedure for extracting DNA from human nucleated cells. Nucleic Acids Res 1988; 16: 1215-7.

[30] Whittle SL, Hughes RA. Folate supplementation and methotrexate treatment in rheumatoid arthritis: A review. Rheumatology 2004; 43: $267-71$

[31] Morgan SL, Baggott JE. Folate supplementation during methotrexate therapy for rheumatoid arthritis. Clin Exp Rheumatol 2010; 28(5 Suppl 61): 102-9.

(C) Taşbaş et al.; Licensee Bentham Open.

This is an open access article licensed under the terms of the Creative Commons Attribution Non-Commercial License (http://creativecommons.org/licenses/by-nc/ 3.0/) which permits unrestricted, non-commercial use, distribution and reproduction in any medium, provided the work is properly cited. 